\title{
Diversidad sexual: la triste historia de una feliz realidad.
}

\section{Sexual diversity: The sad story of a happy reality.}

\section{resumen/ahstract:}

La diversidad sexual es la norma en el ser humano y lejos de sentir temor y rechazo por ella, deberíamos protegerla y promoverla. En este artículo se realiza una revisión acerca de las posibles causas de ese temor hacia la diversidad sexual. Se conceptualiza las diferentes dimensiones en torno a las cuales la sexualidad puede ser vivenciada de formas muy distintas. Se realiza un recorrido para comprender que la heterogeneidad sexual nos ha acompañado desde los inicios de nuestra existencia, cómo ha sido vista por la sociedad y por la ciencia, señalando los hitos fundamentales, los principales autores que han realizado aportaciones relevantes para acabar con una visión categorial de la orientación sexual y cómo ha evolucionado la consideración de la homosexualidad en los diferentes manuales de clasificación de problemas mentales. También se hace referencia a los estragos que causa la LGTBfobia entra las personas que se apartan del heterocentrismo vigente, Ios hitos en la lucha social por los derechos sexuales del colectivo LGTBI, las mejoras legislativas en España y el camino que nos queda por recorrer.

Sexual diversity is the norm in human beings and far from feeling fear and rejection, we should protect and promote it. This paper reviews the possible causes of this fear towards sexual diversity. It conceptualizes the different dimensions around which sexuality can be experienced in very different ways. A historical journey is made to understand that sexual heterogeneity has accompanied us from the beginning of our existence, how it has been seen by society and by science, pointing out the fundamental milestones, the main authors who have made relevant contributions to end up with a categorical vision of sexual orientation and how the consideration of homosexuality has evolved in the different manuals of classification of mental problems. Reference is also made to the havoc caused by LGTBphobia among people who depart from the current heterocentrism, the milestones in the social struggle for the sexual rights of the LGTBI community, the legislative improvements in Spain and the road ahead.

\section{palabras clave/keywords:}

historia, LGTBfobia, hitos, legislación, salud mental, lucha social por los derechos sexuales. history, LBGTphobia, milestones, law, mental health, social struggle for sexual rights.

\section{El miedo a la diversidad sexual}

Un gran despliegue de normas sociales, leyes, mecanismos de control, aparatos de tortura, autos de fe, doctrinas religiosas, etc. han trabajado sin descanso por negar lo innegable y es que el ser humano es capaz de amar y sentirse amado de mil formas. La diversidad sexual es una de tantas diversidades que caracterizan a los seres humanos. Existe una diversidad biológica, cultural, social, étnica, lingüística, religiosa, política, ideológica, de pensamiento, funcional, familiar y por supuesto, también de género y sexual. 
Por más que la diversidad constituya una gran riqueza y un tesoro a nuestro alcance, siempre se topa con un gran enemigo: el miedo a lo diferente. El patriarcado heteronormativo que ha imperado desde los inicios de nuestra historia y la idea de la sexualidad como algo sucio, imperante en la tradición judeocristiana y en los albores de la cultura occidental, hacen que la diversidad sexual todavía se viva como algo más amenazante. Y que para las personas que no responden a la norma, habitar su cuerpo y mostrarse como son se convierta en algo peligroso porque atentan contra la ideología medular que sustenta nuestro sistema social. Esta ideología postula que en el mundo solo hay hombres y mujeres, que los hombres se caracterizan por tener pene y deben ser masculinos y las mujeres lo hacen por tener vulva y deben mostrarse femeninas, y que evidentemente unos deben sentirse atraídos por las otras y viceversa porque la atracción nunca debe darse entre miembros del mismo sexo. En resumen, una gran simplificación porque la realidad nos indica que habitamos un mundo diverso, que la diversidad constituye la norma en todo lo que nos rodea. Son muchas las minorías que sufren discriminación pero hay algo especial en la discriminación que sufren las minorías sexuales y que se deriva de dos factores. El primero es que las minorías sexuales pueden evitar que se note su condición y por lo tanto pueden tener la tentación de ocultarla para evitar el rechazo. Esto hace que la "salida o no del armario" se prolongue a lo largo de toda una vida en según qué contextos y que ésta se convierta en una lucha continua contra la propia identidad. El segundo es que con gran probabilidad, el/la bisexual, homosexual, transexual... vive en una familia donde los restantes miembros no comparten su condición, a diferencia de lo que sucede cuando uno es negro o pertenece a una minoría religiosa. Y eso hace que en demasiadas ocasiones, el ocultamiento, la incomprensión y el rechazo se produzca dentro de la misma familia, del mismo nido donde supuestamente debería una persona sentirte protegida y que la persona LGTBI no tenga el apoyo social ni siquiera de los más cercanos.

\section{¿Qué es la diversidad afectivo-sexual?}

Para entender qué es la diversidad sexual, hay que comprender cuatro conceptos sobre los que ésta se asienta: el sexo, el rol de género, la identidad de género y la orientación sexual. La diversidad sexual se deriva de las grandes diferencias que existen entre los seres humanos en todos y cada uno de estos parámetros y también en la relación que existe entre ellos, de manera que la realidad aparece muy alejada de los dualismos o visiones binarias en cada uno de estos conceptos y de una correspondencia biunívoca entre los mismos.

En primer lugar, el "sexo" se define como el conjunto de características biológicas que permiten categorizar a los humanos como machos o hembras. Aparentemente es la categoría más sencilla de entender. Pero sucede que el sexo biológico se deriva no solo de la aparición de pene-escroto o de vulva-útero (sexo reproductivo) sino de otros criterios como el cromosómico (XY o XX), las gónadas (testículos-ovarios) y las hormonas (preponderancia de andrógenos o de progesterona y estrógenos). Y estos criterios no siempre concuerdan. En ocasiones hay una discrepancia entre el sexo cromosómico, las gónadas y los genitales y en ese caso hablamos de intersexualidad, es decir, de personas que comparten características genéticas y fenotípicas de hombres y de mujeres, por lo que ya biológicamente hablando, 
tenemos a seres humanos macho, hembra e intersexuales. Por si fuera poco, existen numerosos tipos de intersexualidad en función de cómo se combinan las características de macho-hembra en cada individuo.

La “identidad de género”, por su parte, se define como el grado en que cada persona se identifica como hombre o mujer. Pero también aquí nos encontramos con personas que no se identifican con ninguno de los dos géneros, a las que denominamos "agénero" o "transgénero", de manera que desde el punto de vista de la identidad de género tenemos personas que se consideran hombres, mujeres, ninguna de estas cosas o ambas. Es lo que se conoce como "genderqueer", género intermedio, bigénero, género neutro o tercer sexo. En ocasiones el sexo biológico concuerda con la identidad de género y entonces hablamos de personas cisexuales o cisgénero, pero en otras no sucede así y hablamos de personas transgénero o transexuales (aunque existen matices entre estos términos en los que no vamos a profundizar en estos momentos). La persona transexual puede necesitar tener el cuerpo del otro sexo que siente como propio y experienciar el sexo con el que ha nacido con aversión, como una esclavitud y una tortura pero no necesariamente siempre es así, de manera que también hay formas muy distintas de vivir la transexualidad.

En tercer lugar, el "rol de género" consiste en la aceptación como propias de las asignaciones (características en el vestir, manera de ser y comportarse en los diferentes ámbitos, etc.) que la sociedad considera como propias de la mujer o del hombre. Es el conjunto de valores, actitudes, roles, prácticas o características culturales atribuidas a cada uno de los dos sexos. El rol de género está marcado por estereotipos descriptivos (cómo son los chicos y las chicas) y prescriptivos (cómo deben comportarse) que no suelen ser igualitarios ni justos pero que están presionando a los seres humanos desde su nacimiento, a través de la decoración que los padres imponen en sus habitaciones, los juguetes que les compran, cómo les hablan e incluso cómo se comportan con ellos desde la más tierna infancia. Así se establece un sistema de estereotipos de rasgos masculinos que incluyen la estabilidad emocional, autocontrol, dinamismo, agresividad, tendencia al dominio, objetividad, aptitudes intelectuales, aspecto afectivo poco definido, aptitud para las ciencias, racionalidad, franqueza, valentía, eficacia, amor al riesgo... Y otros que serían femeninos como la inestabilidad emocional, la falta de control, la pasividad, ternura, sumisión, dependencia, subjetividad, escaso desarrollo intelectual, aspecto afectivo muy marcado, intuición, irracionalidad, frivolidad, miedo, incoherencia, debilidad... y otra tanta basura ideológica que nos ha estado marcando y castrando durante siglos y siglos. Ya Talcott Parsons en su obra de 1951 The Social System hablaba del rol masculino y femenino, del rol instrumental y expresivo. En esas décadas se consideraba que en la medida en que hubiera una mayor congruencia entre el sexo biológico y el género masculino o femenino, habría una mayor salud mental y viceversa. Sandra Bem (1974) rompió con esta idea al señalar que la masculinidad y feminidad no eran dos extremos de un solo eje sino dos ejes diferentes perpendiculares, de manera que nos encontrábamos con cuatro tipo de personas: altas en masculinidad y bajas en feminidad, altas en feminidad y bajas en masculinidad, altas en masculinidad y feminidad (andróginas) y bajas en masculinidad y feminidad (tipo indiferenciado), señalando que las personas andróginas tendrían más probabilidades de adaptarse a cualquier situación al compartir características 
masculinas y femeninas.

Si bien no es el objetivo de este artículo y por ello no vamos a profundizar en ello, durante años ha existido y sigue existiendo una cierta pugna entre dos posicionamientos teóricos. El que ocupa el esencialismo, que considera que el dimorfismo sexual aparente crea las entidades masculina y femenina que son excluyentes y que tanto sexo como género son aspectos innatos y naturalmente incuestionables. Y por otro lado, el que ocupan las perspectivas postestructuralistas que se basan en dos premisas: (1) Enfatizan el protagonismo individual y la subjetividad de cada persona afirmando que el proceso de construcción de la identidad es de carácter emocional, subjetivo e interior y, por tanto, es mutable; (2) Destacan el papel del relevo sociocultural rechazando el protagonismo que la cultura occidental le ha dado al dimorfismo sexual. De este posicionamiento nace la teoría queer que constituye una fuerte crítica desesencializadora afirmando que el sexo no constituye un único criterio decisorio para establecer las pautas identitarias. Es imprescindible contar con otros componentes que se interrelacionan y combinan continuamente: género, etnicidad, edad, nacionalidad, destrezas o habilidades personales y la interpretación que de cada una de ellas haga cada individuo (Lameiras, Carrera y Rodríguez, 2013). Desde el punto de vista de quien escribe este artículo, cada una de estas posturas tiene su razón de ser. La primera intenta dejar claro que el hecho de ser hombre o mujer constituye un gran condicionante con importantes implicaciones para las vidas y expectativas de los individuos, algo innegable si revisamos la historia y base para la lucha feminista por la igualdad de derechos. Pero la segunda remarca que el ser hombre o mujer no puede ser una condena perpetua que limite de manera determinante la libertad de cada persona para expresar su género y su sexualidad como desee hacerlo.

Finalmente la "orientación sexual" no se define por la forma de comportarse, de hablar o de vestirse de mujeres u hombres, sino por el deseo y/o la atracción sexual que le producen personas de otros o del mismo sexo y es sobre todo a este aspecto de la diversidad sexual al que vamos a dedicar este artículo. Somos conscientes de que nos dejamos muchas otras como la intersexualidad y la transexualidad. Sobre esta última el lector puede revisar el trabajo de Ballester-Arnal (2020).

\section{Principales hitos en la evolución de la perspectiva científica sobre la orientación sexual}

Actualmente podemos afirmar por los testimonios que nos han quedado, que la diversidad sexual ha formado parte de la vida de los seres humanos desde los inicios de su existencia. Tenemos testimonios que nos hablan de prácticas homoeróticas en la antigua Mesopotamia desde el período sumerio (3000 a.C), el antiguo Egipto, Grecia, Roma, la Edad Media y el Renacimiento (Halperin, 1990) y no sólo en la cultura occidental sino también la cultura árabe preislamica, china, japonesa y no digamos la India, que están llenas de pasajes de homoerotismo. E incluso en las culturas precolombinas.

Pero también es antigua la historia de la homofobia o más ampliamente la LGTBfobia. Ya en los siglos XVIII y y sobre todo en el XIX, la homosexualidad pasa a ser considerada menos como un pecado contra natura como se había extendido sobre todo en la Edad Media, y más como una enfermedad (Fone, 2000). Las sotanas negras dejan paso a las batas blancas 
bajo un discurso similar. Krafft-Ebing aseguró en su Psychopathia Sexualis que la homosexualidad era el resultado de taras genéticas y de una debilidad del sistema nervioso, una muestra de su degeneración, que llevaba a la comisión de delitos, atrocidades y en el mejor de los casos, a la patología mental. Freud retomó el tema a finales del siglo XIX y principios del XX y la historia reciente es muy distinta, pero aún no libre de dolor y sufrimiento.

El traspaso de la orientación sexual desde el ámbito de la moral a su estudio científico supuso un paso muy relevante, pero no exento de problemas y de sesgos que provenían de siglos de homofobia (Fone, 2000). Tradicionalmente y especialmente en el ámbito popular se ha entendido la orientación sexual desde una perspectiva dicotómica y muy limitada. En principio, se esperaba de todas las personas que se sintieran atraídas hacia el sexo opuesto (heterosexualidad). Pero en ocasiones eso no sucedía así y podíamos encontrarnos con casos de homosexualidad que supuestamente y según se decía, respondían a algún tipo de alteración biológica o en la historia del individuo al que le sucedía esto. Freud fue uno de los primeros autores que rompieron con esta visión binaria de la orientación del deseo sexual. Sus escritos más importantes sobre la homosexualidad fueron escritos entre 1905, cuando publicó “Tres ensayos sobre la teoría de la sexualidad”, y 1922, cuando publicó "Ciertos mecanismos neuróticos en celos, paranoia y homosexualidad". En esos escritos, Freud frecuentemente llamó a la homosexualidad una "inversión", algo que en su opinión era diferente de las perversiones necesariamente patológicas, y sugirió que podrían existir varios tipos distintos. Y también aseguró que algunas personas se podían sentir atraídas indistintamente hacia un sexo u otro y por lo tanto, había una tercera orientación, la bisexual. Y no solo eso, Freud fue más lejos al asegurar que la bisexualidad era la condición innata del individuo y que era la fuerza del "super-yo", la que iba reconduciendo poco a poco los impulsos del "ello", hasta darles una forma aceptable para la sociedad.

Podríamos considerar que Freud fue uno de los primeros activistas LGTBI al realizar este tipo de consideraciones, si no fuera porque él mismo se encargó de matizar que si el desarrollo psicosexual del individuo se producía correctamente el individuo acabaría siendo heterosexual, pero si se daba otras cosas como la envidia de pene, envidia de vagina, no se superaba adecuadamente el complejo de Edipo, había una fijación de la persona a alguna de las fases de su desarrollo que le impedía avanzar o se producía un narcisimo que imperaba sobre la personalidad, la homosexualidad podía quedarse como orientación definitiva. En pocas palabras, aunque las personas nacían bisexuales, si todo funcionaba correctamente, llegarían a la heterosexualidad, pero si había algún problema en el camino, podían desembocar en la orientación opuesta y ser unos "invertidos". Estas teorías fueron formuladas a finales del siglo XIX y principios del XX, es decir, hace ya mucho tiempo y sin embargo, la mayoría de las personas siguen pensando que existen solo tres tipos de orientación sexual. Pero la realidad es tozuda y muy distinta como veremos más adelante.

Un autor coetáneo de Freud pero menos conocido fue Havellock Ellis que abordó el tema de la homosexualidad en su obra "Inversión sexual". Este autor prescindió de la teoría de la degeneración y la idea de que la masturbación podía llevar a la homosexualidad de KrafftEbing, se opuso a los tratamientos para curar la homosexualidad y aunque no llegó a decir que la homosexualidad era normal, le quitó mucha carga patológica y de hecho las personas 
de las que habla en su obra no son delincuentes que realizaban atrocidades como sucedía en "Psychopathia Sexualis" sino gente corriente. Más transgresor todavía durante esa época fue Hirschfeld, un psiquiatra que fundó en Alemania el Comité Científico y Humanitario para avanzar en la causa de la emancipación de los homosexuales en su país y creó el Instituto para la Ciencia Sexual de Berlín. Pero su proclama de la igualdad legal que debían tener los homosexuales fue ignorada, en parte por ser judío pero también por su declarada homosexualidad (Mondimore, 1998). Y sobre todo, un dictador, Hitler se encargaría de silenciar todo su legado.

El que sí resultó una verdadera revolución fue Alfred Kinsey. Este autor, junto a W. Pomeroy y C. Martin, publicaron en el año 1948 su obra "Sexual Behavior in the Human Male", en la que afirmaban ciertas cosas que fueron demasiado transgresoras para la moral de la época (cinco años más tarde publicó su "Sexual Behavior of the Human Female"). El resultado fue que, a pesar de ser considerado ya un científico de prestigio, nada más salir a la venta en los Estados Unidos, el libro fue retirado de las librerías y no volvió a ellas hasta ocho años después. Además de señalar que la masturbación era una práctica habitual en la población general y otras cuantas groserías por el estilo, Kinsey se atrevió a decir que la orientación sexual no era un constructo dicotómico sino unidimensional, de manera que las personas podían ser más o menos heterosexuales u homosexuales. En una escala de siete puntos, sólo el $50 \%$ de los hombres aseguraban sentirse atraídos exclusivamente por el sexo opuesto frente al $10 \%$ que solo se sentían atraídos hacia el mismo sexo y un amplísimo $40 \%$ se situaba en los puntos intermedios entre ambas orientaciones exclusivas. En las mujeres estos porcentajes se convertían en el $81 \%$ de heterosexualidad exclusiva, el $6 \%$ de homosexualidad exclusiva y el $13 \%$ con una orientación intermedia en torno a la bisexualidad. El estudio se había realizado con la población general y con cerca de veinte mil hombres y otras tantas mujeres, así que era difícil menospreciarlo. La obra de Kinsey fue fundamental en la historia de cómo se ha considerado científicamente la orientación sexual al romper con las etiquetas exclusivas y las categorías prefijadas que se utilizaban hasta la fecha y al mismo tiempo demostrar que era una buena proporción de la población y no unos cuantos, los que no encajaban a la perfección con esas categorías.

Un autor menos conocido pero también muy relevante fue Michael Storms. Este autor, en el año 1980 propuso una nueva forma de evaluar la orientación utilizando en lugar de una escala unidimensional, dos ejes X (homosexualidad u homoerotismo) e Y (heterosexualidad o heteroerotismo). De esa manera se superaba la limitación del eje unidimensional de Kinsey que suponía que cuanto más atracción había hacia el mismo sexo, menos la había hacia el sexo contrario. La escala de Storms permitía visualizar a personas que sentían una alta atracción tanto hacia hombres como hacia mujeres, alta hacia unos y baja o nula hacia otros, o baja atracción hacia ambos, e incluso ninguna atracción hacia ningún sexo en el caso de las personas asexuales. Por tanto, la contribución de Storms es que plantea la orientación sexual como algo menos lineal, incluye las variaciones en la orientación no solo sobre la dicotomía hetero/homo, e incluye una identidad asexual. Actualmente estamos asistiendo a una importante reivindicación de esta identidad de la orientación sexual. Si bien las personas que no se sienten atraídas ni por hombres ni por mujeres han sido tachadas de reprimi- 
das o de padecer un trastorno por bajo deseo sexual, los asexuales reivindican su derecho a no sentir esa atracción sin por ello estar sufriendo ningún trastorno. A partir de aquí, se han realizado numerosas clasificaciones de los distintos tipos de asexuales que no enumeramos en aras de la brevedad.

Pero a nuestro parecer fue Klein (1985) quien otorgó a la orientación sexual toda la complejidad que merece. Este autor, en su obra "La opción bisexual", recoge la escala de siete puntos de Kinsey, pero no la mantiene en su versión original unidimensional sino convirtiéndola en multidimensional, de manera que la aplica a la atracción sexual, el comportamiento sexual, las fantasías, la preferencia emocional, la preferencia social, el estilo de vida y la autoidentificación. En cada una de estas dimensiones, la persona podría situarse entre los extremos 1 (solo hacia el otro sexo) y 7 (solo hacia el mismo sexo). Pero por si fuera poco, Klein defiende que la orientación sexual puede evolucionar en el tiempo, de manera que el individuo podría situarse en un punto dentro de esta rejilla en el pasado, en el presente o en su yo-ideal aceptando de esta manera que posiblemente el individuo está expresando su orientación sexual no de la manera que desearía como consecuencia por ejemplo de presiones sociales.

Si nos situamos en el marco de las categorías, hoy podríamos decir que con cierta frecuencia nos podemos encontrar con personas heterosexuales, homosexuales, bisexuales, asexuales y cada tanto aparecen nuevas categorías que intentan apresar una realidad compleja. No es momento de mencionarlas aquí todas, entre otras cosas porque estamos ante una proliferación no siempre rigurosa, pero sí merece la pena destacar la categoría de la pansexualidad que caracteriza a las personas que sienten atracción por otras de distintos sexos biológicos y distintas identidades y expresiones de género, lo que significa que un pansexual se puede sentir atraído por una persona biológicamente macho, hembra o intersexual y desde el punto de vista del género, hombre, mujer o transgénero. Desde el punto de vista práctico, a veces la diferencia entre bisexualidad y pansexualidad es nula pero sí la hay desde el punto de vista del posicionamiento teórico. Los defensores de la etiqueta "pansexual" mantienen que el término "bisexual" es heredero de una tradición que defiende la existencia de dos sexos y dos géneros, mientras que la pansexualidad renuncia al carácter binario de los sexos y los géneros y por lo tanto se sitúa en una perspectiva del género postestructuralista o queer.

\section{¿La muerte de las categorías en la visión de la orientación sexual?}

¿Significa la visión dimensional de la orientación sexual que ya propuso Kinsey la muerte de las categorías? En absoluto. El ser humano tiende a las clasificaciones y las etiquetas. Son cómodas y permiten situarse en un punto y ya no tener que reflexionar demasiado sobre el asunto. Por otro lado, las categorías tienen sus aspectos positivos. Si el considerarme gay o mujer me da una identidad que me permite luchar contra la discriminación que han sufrido los homosexuales y las mujeres y reivindicar el respeto a mis derechos en la sociedad en la que me ha tocado vivir, esa identificación puede ser útil y práctica. Pero siempre que no se nos olvide que estamos hablando de una construcción, de algo imaginado y no de una realidad fija e inmutable. En el mismo instante en el que una etiqueta o categoría nos impide comprendernos a nosotros mismos o a los demás, crecer y seguir evolucionando, 
hemos de dinamitar la categoría y hacerla saltar por los aires. No hay ningún problema en que yo me considere una mujer lesbiana, siempre y cuando, sea capaz de entender y aceptar que en algún momento me atraiga un hombre determinado o incluya a hombres en mis fantasías sexuales y me quiera comportar más masculina o femeninamente. Si no es así, si la identidad como mujer lesbiana me constriñe y empobrece, entonces la categoría ha pasado a convertirse en un problema.

Para hacernos una idea, en un estudio piloto (Ballester-Arnal y Gil-Llario, 2016) que realizamos en nuestro equipo con 316 jóvenes entre 18 y 23 años, de los cuales el 48,1\% eran hombres y el resto, mujeres, un $85,4 \%$ se identificaron como heterosexuales $(80,9 \%$ de hombres y $89,6 \%$ de mujeres), un $9,2 \%$ como homosexuales $(15,8 \%$ de hombres y $3 \%$ de mujeres) y un $5,4 \%$ como bisexuales (3,3\% de hombres y 7,3\% de mujeres). Hasta aquí, poco que decir. Cuando modificamos la pregunta e inquirimos si alguna vez la persona había sentido deseo hacia el mismo sexo, el porcentaje, que debería haber sido teóricamente la suma de los homosexuales y bisexuales, es decir, 14,6\%, sin embargo pasaba al $32 \%$ (27,6\% de hombres y $36 \%$ de mujeres), algo muy similar a cuando preguntamos por sus fantasías sexuales. Y cuando preguntamos si alguna vez habían tenido relaciones homoeróticas, el porcentaje fue del 15.8\% (19.7\% de hombres y $12.2 \%$ de mujeres). ¿Qué significa esto? Es sencillo: si queremos comprender la orientación sexual las categorías se nos quedan cortas. Puede ser importante conocer qué se considera uno/a pero hay que seguir preguntando. Cuando preguntamos cuántos se consideraban heterosexuales, el resultado fue del 85,4\%, pero cuando aplicamos la escala Kinsey, solo un 64,9\% afirmó sentirse atraido solo hacia el otro sexo, situándose el resto a lo largo del continuo. Concretando los análisis, pudimos descubrir que de entre quienes se consideraban heterosexuales, el 20,7\% tenía deseos homoeróticos, el 21,9\% incluía al mismo sexo en sus fantasías y el 3\% incluso había tenido relaciones homosexuales. Y lo mismo sucede entre quienes se consideraban homosexuales con el $34,5 \%, 20,7 \%$ y $24,1 \%$ respectivamente. En resumen, lo que la evidencia empírica nos indica es que hay diversidad dentro de la diversidad o lo que es lo mismo, la diversidad es la norma.

Si incluimos en una coctelera los diferentes sexos (hembra, intersexual o macho), identidades de género (mujer, transgénero o agénero y hombre), las expresiones de género (femenino, andrógino o masculino) y las orientaciones sexuales (homosexual, bisexual, heterosexual, pansexual y asexual), y la agitamos bien, la bandera arcoiris se queda corta para expresar la maravillosa diversidad existente en la sexualidad humana, de manera que será difícil encontrar dos personas que vivan de la misma forma su sexo, su género y su orientación sexual.

\section{La lucha social por los derechos LGTBI}

En el año 1973, por primera vez la homosexualidad fue suprimida de la lista de enfermedades mentales (DSM) por la Asociación de Psiquiatras Americanos. Pero esta eliminación y la consiguiente consideración del comportamiento homosexual como "normal" o "no patológico" no llovió del cielo. El conocido mayo de 1968 con sus revueltas estudiantiles en Paris propugnaba entre otras cosas la liberación sexual, lo que fue el caldo de cultivo para 
el nacimiento del FHAR (Front Homosexuel d'Action Revolutionnaire). Un año más tarde se produjo un acontecimiento que dejaría una huella profunda. El 28 de junio, en el bar Stonewall Inn de Nueva York al que solía acudir la comunidad gay de Greenwich Village, hubo una redada con una excesiva violencia policial que acabó con 13 detenidos. Al día siguiente centenares de gays salieron a la calle para protestar por la represión de la comunidad homosexual manifestando el hartazgo que habían causado las redadas en bares de ambiente gay.Y el 27 de julio se produjo la primera gran marcha de gays y lesbianas en Nueva York. La revuelta dio lugar al grupo Gay Liberation Front, uno de los gérmenes más activos de la lucha por los derechos LGTB. Pero el respeto hacia la comunidad homosexual ha tenido que ser ganado a pulso, paso a paso, demasiado lentamente y con demasiado sufrimiento. En el recuerdo queda el impacto que causaron películas como Brokeback Mountain en el imaginario estadounidense, una historia de amor homosexual nada menos que entre dos cowboys, el símbolo legendario de la masculinidad en Estados Unidos. Ha hecho falta que referentes de prestigio en el ámbito del deporte como Jason Collins de la NBA o el clavadista británico Tom Dealey medallista de los juegos olímpicos de Londres 2012, o cantantes de gran fama como Ricky Martin o más recientemente Pablo Alborán, "salieran del armario", para que la homosexualidad haya empezado a estar algo más normalizada. Sin embargo, todavía demasiadas personas sufren lo indecible para decir a los demás o a sí mismos, que se sienten atraídos por el mismo sexo o por ambos o que no se sienten identificados con el cuerpo que tienen, mientras la comunidad científica y gran parte de la población se siguen preguntando de manera esteril y absurda, por la causa de la homosexualidad o la transexualidad.

\section{Las causas de la homosexualidad o la búsqueda del Santo Grial}

Durante las últimas décadas, la ciencia ha cogido el relevo no solo en el estudio de las múltiples expresiones de la orientación sexual sino también en la indagación de sus causas. Siempre desde el humilde punto de vista de quien escribe estas líneas, de todas las preguntas que se han formulado los científicos, hay pocas tan absurdas como intentar encontrar una explicación, incluso a veces biológica, al comportamiento homosexual, más allá del evidente sustrato biológico sobre el que se asienta toda conducta humana.

Se han formulado teorías que han sugerido que la determinación de la orientación sexual de un individuo depende del estructura y desarrollo del hipotálamo (Swaab y Hofman, 1990), de causas genéticas (Bailey y Pillard, 1991, citado en Ballester y Gil, 1995; Hamer, 1993) o de la acción de las hormonas durante el desarrollo fetal (Swaab y Garcia-Falgueras, 2009). Por otro lado, otros autores han buscado una explicación psicológica a la homosexualidad: eventos conscientes o inconscientes durante el desarrollo del individuo, como las teorías freudianas de represión de impulsos.

Sin embargo, ya hace cuatro décadas Bell y Weinberg en 1978 en su obra "Homosexualities" afirmaron que probablemente no hay una sola causa o conjunto de factores que invariablemente determinen la orientación del deseo sexual, ni las mismas causas en todos los individuos, ni siquiera entre aquellos que tienen la misma orientación y que ésta siempre se debe a una interrelación de distintos factores. Posteriormente en 1981 estos autores publicaron la obra "Sexual Preference" en la que presentaron los resultados de entrevistas a 979 ho- 
mosexuales y 477 heterosexuales hombres y mujeres, concluyendo que se puede hablar de una homosexualidad predisposicional y también de una responsividad homosexual aprendida, con menor o mayor carga de factores ambientales ligados al desarrollo y el aprendizaje en uno u otro tipo.

Desde nuestro punto de vista, todas estas teorías han sido intentos vanos por encontrar una explicación a una pregunta mal formulada desde el principio. ¿Por qué preguntarse por las causas de la homosexualidad y no de la heterosexualidad? Si la única respuesta a esta pregunta es que hay más personas heterosexuales que homosexuales, busquemos también cuáles son los factores responsables de que a una persona le guste más la carne que el pescado, los garbanzos que las alubias o la montaña que el mar. Si la respuesta es que la heterosexualidad se explica sola por la necesidad reproductiva, preguntémonos en qué porcentaje de nuestra actividad sexual estamos buscando reproducirnos y cuando lo que buscamos es otra cosa como sentir o dar placer o afecto, ¿por qué no podríamos buscarlo indistintamente en hombres o en mujeres? Y si todo ello no fuera suficiente, hagámonos la pregunta de qué es lo que pretendemos explicar: ¿los comportamientos homosexuales, los deseos, las fantasías, la etiqueta que cada uno se pone? ¿Cómo debería ser el hipotálamo o los genes de una persona que tiene relaciones heterosexuales pero fantasea con el mismo sexo cuando se masturba? ¿Más grande o más pequeño que el que tiene relaciones con ambos sexos, o el homosexual que a veces tiene fantasías con el otro sexo? Solo el planteamiento ya suena ridículo y quizás estemos intentando ponerle puertas al campo o encontrar el Santo Grial que ayude a sustituir la visión de los homosexuales y bisexuales como pecadores o degenerados por otra que nos deje científicamente más tranquilos pero que sea igualmente limitada en la comprensión de la diversidad de la sexualidad humana.

\section{La consideración de la homosexualidad en las Clasificaciones Internacionales de Enfermedades}

Como es sabido, en 1952 se publicó la $1^{\text {a }}$ edición del Manual Diagnóstico y Estadístico de los Trastornos Mentales (DSM) de la Asociación de Psiquiatría Americana (APA) con el fin de homologar las distintas clasificaciones de enfermedades mentales que había hasta entonces. En esta primera edición, la APA incluyó a la homosexualidad como una enfermedad mental dentro de las "Desviaciones sexuales", a pesar de la escasa y la poco rigurosa evidencia de una cierta asociación entre esta orientación sexual y problemas emocionales. Evidentemente, el criterio de malestar subjetivo y el de interferencia en la vida del individuo, como criterios para delimitar lo normal de lo patológico son relevantes. Pero esos criterios resultan relativos cuando estamos hablando de una dimensión de nuestras vidas en la que el malestar y la interferencia provienen no de la propia conducta en sí, sino del modo en que el entorno social la valora (Ballester-Arnal, 2020).

En la $2^{\text {a }}$ versión de este manual (DSM-II), se eliminó la homosexualidad como categoría diagnóstica de la sección de "Desviaciones Sexuales" (APA, 1973). Como se ha dicho, esto ocurrió como consecuencia de la evidencia de que la única patología encontrada en las personas homosexuales era la que se podía derivar de su estigma social, y del impulso dado por los movimientos sociales en defensa de las libertades sexuales de la comunidad gay en 
USA. Pero esta decisión del consejo de administración de la APA generó una gran controversia, tanta que por primera y última vez en la historia de la APA, sus veinte mil miembros forzaron que se votara esta decisión. En 1974, la APA confirmó oficialmente su decisión de eliminar la homosexualidad del DSM-II en una votación ajustada (lo apoyó solo el 58\% de los miembros). La Asociación decidió sustituir este diagnóstico por la categoría de "Perturbaciones en la Orientación Sexual", sin hacer ya mención expresa a la homosexualidad en su título.

En 1980, en la $3^{\text {a }}$ edición del manual (DSM-III), se dio un cambio importante en el modelo de clasificación con un fuerte énfasis en la necesidad de limitar las categorías diagnósticas a aquellas patologías de la que hubiera evidencia empírica. En esta edicion se incluyó el diagnóstico de "Homosexualidad Egodistónica", refiriéndose al persistente e intenso malestar sobre la orientación sexual propia. Pero seguía apareciendo el término "homosexualidad" (un precio que hubo que pagar ante el reintento por parte de un sector de la APA de que volviera a restaurarse la homosexualidad como trastorno mental), de modo que este último diagnóstico fue definitivamente eliminado en 1986 de la versión revisada de esa misma publicación (DSM-III R) (APA, 1988) donde ya aparece solo una categoría de "Trastornos sexuales no especificados" en la que se hace mención al "Malestar en torno a la orientación sexual", categoría que se mantuvo en el DSM-IV (APA, 1995), en el DSM-IV-TR (APA, 2001) y en la actualidad, en el DSM-5 (2013).

Por su parte, hubo que esperar al 17 de mayo de 1990, para que la Organización Mundial de la Salud (OMS) se uniera a la eliminación de la homosexualidad de la Clasificación Internacional de Enfermedades y otros Problemas de Salud (OMS, 1992), de manera que en la CIE-10 ya no apareció como tal y por supuesto tampoco en la CIE-11.

Por tanto, hace como mínimo 30 años que ninguna clasificación de enfermedades entiende la homosexualidad como un trastorno. Como afirman Moser y Kleinplatz (2008) el espectro de estímulos, humanos o no, que pueden atraer a una persona es amplísimo y para patologizar un interés sexual se debe tener datos que lo confirmen, como mayor garantía para no caer en la crueldad de estigmatizar a ninguna persona ni colectivo sin ningún fundamento. La homosexualidad tenía que desaparecer de los manuales psiquiátricos porque no había un solo dato que sustentara que las personas con esta orientación tuvieran un perfil psiquiátrico ni psicopatológico específico (De Block y Adriaens, 2013).

A pesar de todo ello, todavía se puede encontrar "personajes" que venden terapias de "reorientación sexual", "de conversión", "reparativas" o de "deshomosexualización", a partir de procedimientos pseudocientíficos que no solo carecen de evidencia sino que pueden causar graves daños psicológicos a la persona que los recibe, por lo que son fervientemente desaconsejados, no éticos e incluso ilegales en muchos países.

\section{Otras pandemias: la LGTBfobia}

El único problema y la única enfermedad, que ha llegado a niveles de pandemia, con la que nos topamos y cuya causa habría que explicar y atender es la LGTBfobia que hace que todavía en alrededor de 70 países del mundo se persiga a los gais, las lesbianas, los bisexua- 
les y los transexuales y que en algunos de estos países se condene su comportamiento con cadena perpetua o con la misma muerte. Parece claro que las personas homosexuales no son ni pecadoras, ni pervertidas, ni viciosas, ni enfermas, ni un riesgo para la salud y la moral públicas. ¿Cuesta tanto comprender que son personas normales, de carne y hueso como todas las demás?

Pero si la homosexualidad no ha sido entendida fácilmente por la población general, aún menos la bisexualidad. Algunos han argumentado que las personas bisexuales tienen una especie de conflicto con su identidad, son promiscuos, incapaces de estar con una única pareja, presentan inmadurez sexual, indefinición transitoria o un estado de confusión respecto a su sexualidad, en lugar simplemente de una flexibilidad que puede llegar a ser incluso adaptativa. Ya hace mucho tiempo Zinik (1985) encontró que efectivamente el $79 \%$ de bisexuales hombres o mujeres había sentido algún conflicto y confusión, pero no por su orientación sexual sino sobre todo por la falta de apoyo social o la complejidad psicosocial inherente a la bisexualidad. Por otro lado, es justo reconocer que se trata de una orientación que ha sido estigmatizada no solo por los heterosexuales sino también por los propios homosexuales que en ocasiones los han considerado algo así como unos cobardes que no se atreven a confesar definitivamente su orientación y que utilizan esa doble vertiente para escabullirse en las situaciones sociales más comprometidas. Para Angelides (2001) y Alexander y Anderlini-D’Onofrio (2012), comprender la bisexualidad es comprender la naturaleza de la sexualidad del ser humano. Se trataría según estos autores de una orientación fundamental para el conocimiento de la sexualidad tal como es concebida desde la teoría queer, cuyo estudio desde el punto de vista científico ha sido olvidado a favor de otras identidades excluyentes como la hetero o la homosexualidad. Estos autores señalan que la identidad de la bisexualidad no está clara. ¿Se trata del estado natural del ser humano sobre el que se ha forzado la elaboración de dos orientaciones extremas y exclusivas, la de la homosexualidad y la de la heterosexualidad? ¿O más bien lo que resulta forzado y una invención es la etiqueta de la bisexualidad que se refiere más a un comportamiento concreto y temporal en ese continuo entre la homosexualidad y la heterosexualidad, que a una identidad en sí misma?

Otra de las cuestiones que más llama la atención es la mayor homofobia en hombres que en mujeres. Elisabeth Badinter (1993), en su obra "XY: La identidad masculina" lanza una hipótesis interesante que intenta explicar este hecho. Según esta autora, las mujeres tienen un referente biológico que marca el paso de la niñez a la adultez: la menstruación. Pero en los hombres no existe y eso explicaría la existencia en casi todas las culturas de ritos de iniciación a la masculinidad, ritos que pueden ser muy diversos (separación de la madre, abandono en la selva, caza del león, actos que implican sufrimiento físico, etc) pero que tienen en común el provocar un estado de tensión máxima, de vergüenza y de humillación que ayuda a que el hombre pierda su parte femenina (¿o su sensibilidad?). Según esta autora, la identidad femenina es fuerte pero la identidad masculina es frágil porque se define justamente por lo que no es. Un hombre se pasa la vida demostrando que no es un niño, que no es una mujer y que no es homosexual y solo a través de esa triple negación consigue su carnet de identidad como hombre. Su necesidad de negar la homosexualidad tiene que ver en muchas ocasiones con la de reforzar su identidad masculina. 
El rechazo a la homosexualidad y en general la LGTBfobia tiene múltiples expresiones, algunas más manifiestas y otras más sutiles, pero su impacto psicológico siempre es tremendo y cruel. Sin embargo, de todos sus efectos quizás el más devastador es el odio que se inocula en la persona que se aparta de la norma y que acaba siendo interiorizado y dirigido contra uno mismo, lo que denominamos la "homofobia internalizada". De hecho, un/a homosexual o bisexual, primero aprende que ser así está mal y después, que él/ella es así, es decir, construye su identidad en torno a ese rechazo hacia sí mismo. No hay peor forma de causar daño que introducir al enemigo dentro de uno mismo.

Por citar algunos datos relevantes, un estudio de Avilés en nuestro país (2006) señaló que existía un elevadísimo porcentaje de estudiantes que habían sufrido múltiples formas de acoso como consecuencia de su orientación sexual como ser ridiculizados públicamente ( $75 \%$ de hombres y $54 \%$ de mujeres), ser golpeados o recibir patadas ( $68 \%$ y $31 \%$ respectivamente), sufrir rumores hacia su persona (57\% y 67\%), ser víctimas de bromas (58\% y $56 \%)$, ser asustados o intimidados (54\% y $44 \%)$, sufrir el robo de sus pertenencias (47\% y $31 \%)$, ser aislados socialmente ( $24 \%$ y $41 \%)$ e incluso sufrir abuso sexual (13\% y $5 \%$ ).

Respecto a otros países, un metaanálisis de Rothman, Exner y Baughman (2011) con 139.635 estadounidenses LGB señaló que entre un $12 \%$ y un 54\%, de hombres gays y bisexuales habían sufrido alguna agresión sexual a lo largo de su vida con un promedio del $30 \%$. Entre las mujeres lesbianas y bisexuales, los datos eran de un $16 \%$ a un $85 \%$ con un promedio del $43 \%$. Como contraste, téngase en cuenta que en población general los índices son de $2-3 \%$ en hombres y $11-17 \%$ en mujeres.

Por su parte, Mitchell, Ybarra y Korchmaros (2013) realizaron un estudio con una población más concreta, la de adolescentes entre 13 y 18 años $(n=5907)$. Los resultados indicaron que un 23-72\% sufrieron acoso sexual en el ultimo año, con el mayor índice en chicas queer/lesbianas (72\%), chicas bisexuales (66\%) y chicos queer/gays (66\%). En función de la identidad de género, los adolescentes trans informaron los mayores índices de acoso (81\%), seguido de mujeres cisgénero (52\%) y hombres cisgénero (34\%). Además la mitad de las chicas bisexuales, lesbianas y queers acosadas, y el 63\% de los transgénero manifestaron haber sufrido malestar en la escuela, familia o amigos. Por otro lado, la experiencia de acoso estuvo relacionada con menor apoyo social y más baja autoestima.

La inseguridad de los adolescentes LGTB se da incluso en los ámbitos más íntimos. Así Ray (2006) encontró que más de la mitad de los adolescents LGB sufren una reacción negativa de los padres cuando revelan su orientación sexual, incluyendo que les echen de casa (26\%) o ser agredidos físicamente por miembros de la familia (33\%). Kosciw et al. (2011) hallaron que más del $60 \%$ de los adolescentes y jóvenes LGB manifiestan sentirse inseguros en la escuela como consecuencia de su orientación, tener problemas de autoestima y peores notas que con el tiempo pueden limitar su acceso al trabajo. Friedman y Leaper (2010) en otro estudio indicaron que los adolescentes LGTB en USA presentan 3,8 veces más probabilidades de padecer abuso sexual, 1,2 más probabilidades de sufrir agresiones físicas de los padres, 1,7 veces más agresiones en la escuela y 2,4 veces más abandono de la escuela por miedo. Pero hay muchas formas de discriminación, algunas más sutiles. Por ejemplo, Platt y 
Lenzen (2015) hablan de las ocasiones en que el entorno niega la cuestión de su orientación o identidad sexual de no ser que ya se tenga una relación de pareja y sea evidente.

Evidentemente la LGTBfobia no es inocua y tiene un fuerte impacto en la salud mental de este colectivo. Por citar algunos estudios, Cochran (2001) encontró que las personas LGTB padecen más depresión, abuso de sustancias y suicidio. Meyer (2003) afirmó que los gays y lesbianas tienen 2,5 veces más probabilidades de padecer problemas de salud mental comparados con los hetero. Almeida et al. (2009) en su estudio con adolescentes LGTB entre 13-19 años, halló que éstos presentan más síntomas depresivos, autolesiones (21\%) e ideación suicida $(30 \%)$ que los heterosexuales (6\% y $6 \%$ respectivamente), mediados por la discriminación percibida. También Lehavot y Simoni (2011) inciden en este hecho al hallar que los problemas de salud mental y uso de sustancias en mujeres lesbianas y bisexuales están asociados a una mayor victimización, homofobia internalizada y menos recursos psicosociales. Finalmente, el estudio de Chard et al., (2015) realizado en siete países (n=3500 hombres gays y bisexuales) encuentra igualmente que las experiencias de discriminación están asociadas a padecer más problemas mentales (depresión, ansiedad...) e incluso al suicidio. Estos autores explican los resultados a partir de la teoría del estrés de minoría señalando que el rechazo de su identidad conduce a padecer homofobia internalizada, estigma percibido y actos reales de discriminación. También puntualizaron que los hombres bisexuales sufren mayor homofobia internalizada que los gays y que la existencia de redes sociales de apoyo disminuye la homofobia internalizada.

Por si fuera poco el estigma que sufre cualquier persona LGTB, en ocasiones éste se ve multiplicado por tres. Un caso extremo es la invisibilización de las mujeres lesbianas mayores. A la invisibilización de la sexualidad femenina por parte de la población general, se une la del lesbianismo por parte de la mayoría heterosexual y la de las personas mayores por parte de las lesbianas jóvenes. Un estudio de Averett et al., (2013) mostró que las lesbianas mayores (de 51 años) sufren discriminación en el puesto de trabajo, de compras, en restaurantes, relaciones familiares, situaciones sociales, sistema sanitario, e incluso en la búsqueda de casa...

\section{Mejoras legislativas}

Ya hemos dicho que aunque es cierto que la diversidad sexual existe desde los inicios de la humanidad, también lo es que la homofobia no tiene menor antigüedad y que las personas que se han apartado de la norma heteropatriarcal han sido duramente reprimidas a lo largo de la historia por la ley y castigadas incluso con la propia pena de muerte. Tras el horror sembrado por la Santa Inquisición en nuestro Siglo de Oro, en España se produjo un cambio importante en la Ilustración, una época en que las libertades sexuales eran más respetadas, lo que llevó a la desaparición en 1822 de la sodomía del Código Penal. La difícil y paulatina apertura hacia los comportamientos homosexuales se topó un siglo después con la dictadura franquista y su Ley de Peligrosidad Social que en su artículo segundo señalaba que "serán declarados en estado peligroso, y se les aplicarán las correspondientes medidas de seguridad y rehabilitación (...) los que realicen actos de homosexualidad”. La dictadura volvió a reprimir duramente cualquier expresión no heterosexual o que no entrara dentro de 
los cánones estrechos que marcaba la moral pública. La transición a la democracia volvió a abrir lentamente el proceso de apertura y de reconocimiento de los derechos sexuales del colectivo LGTB. Desde el punto de vista legal, es innegable que en España se han producido importantes avances en los últimos años y de hecho nuestro país se consideró en el año 2018 el sexto país más avanzado en materia legislativa de protección de los derechos LGTB en el mundo. La protección más significativa es la que presta el artículo 14 de la Constitución Española, que prohíbe la discriminación por cualquier condición o circunstancia personal o social, entre las que se incluye la orientación sexual e identidad de género. Un hito fundamental fue la legalización del matrimonio homosexual el 3 de julio de 2005, convirtiéndose nuestro país en el tercero del mundo en hacerlo, después de Países Bajos (2001) y de Bélgica (2003). También la adopción homoparental, aunque ya en dos leyes de 1987 y 1988 se había legalizado de facto si bien solo parcialmente. En lo que respecta a los derechos de la comunidad transexual, España aprobó en 2007 la ley de identidad de género, que permite el cambio de nombre y sexo en el Registro Civil, siempre que la inscripción inicial no se correspondiese con su verdadera identidad de género y se cumplan ciertos requisitos.

Además, en 2013, el Ministerio del Interior informó que casi el 31\% de los delitos de odio que se produjeron en España fueron por motivos de orientación e identidad sexual, lo que llevó al desarrollo de leyes que amparan a las personas LGTBI frente a cualquier tipo de agresiones o discriminación que puedan sufrir como la Estrategia Valenciana para la Igualdad de Trato, la No discriminación y la Prevención de los Delitos de Odio 2019-2024 publicada el 6 de febrero de 2019. De hecho, a nivel nacional el Código Penal considera como agravante (circunstancia que incrementa la responsabilidad penal) cuando el delito se comete por la orientación o identidad sexual de la víctima. La misma normativa prohíbe expresamente la discriminación en el trabajo (artículo 314) y en el acceso a los servicios públicos o privados (artículos 511 y 512) si esta se produce por razón de sexo u orientación sexual. Asimismo, prohíbe las asociaciones que fomenten, promuevan o inciten directa o indirectamente al odio, hostilidad, discriminación o violencia contra personas, por su orientación sexual y penaliza el discurso de odio por este motivo.

En los últimos años distintas comunidades autónomas han aprobado otras leyes que pocos años antes habrían sido impensables como la Ley 8/2017 del 7 de abril denominada "Ley integral del reconocimiento del derecho a la identidad y la expresión de género en la Comunitat Valenciana", una ley en la que se reconoce la eliminación de la consideración de la transexualidad como una enfermedad, la supresión del requisito de aportar o acreditar documentación médica para obtener la documentación administrativa con el género sentido y el acceso a los tratamientos, incluidos los bloqueadores hormonales en la pubertad. Y de nuevo a nivel nacional, el 12 de mayo de 2017 fue aprobada la "Proposición de Ley contra la discriminación por orientación sexual, identidad o expresión de género y características sexuales, y de igualdad social de lesbianas, gais, bisexuales, transexuales, transgénero e intersexuales", conocida como la Ley de Igualdad LGTBI. 


\section{Quo vadis?}

La sexualidad humana es un verdadero crisol donde la única norma es la diversidad, una diversidad que lejos de asustar, diagnosticar y medicalizar, deberíamos respetar, cuidar y promover (Ballester-Arnal, 2020). En lo que respecta a la diversidad sexual, a pesar de los avances indiscutibles, tenemos una enorme tarea por hacer.

En primer lugar, existe una urgente necesidad de programas de educación sexual en las escuelas y también a nivel comunitario (campañas de medios de comunicación bien cuidadas) que sigan normalizando la diversidad sexual, pero además esos programas deben lanzarse desde edades muy tempranas, mucho antes de que la LGTBfobia se haya instalado en las mentes. Los programas actuales son breves, tardíos y con contenidos excesivamente limitados. Debemos ir más allá de la prevención de embarazos no deseados o la prevención de ITS y empezar a hablar de sexualidad saludable, afectos, autoerotismo, disfrute, orientación sexual, género y libertad sexual. Es fundamental que prestemos más atención a las formas internalizadas de homo/bi/trans-fobia que tanto daño pueden hacer a la salud mental del individuo que se aparta de la norma. Hay que hacer un mayor esfuerzo por visibilizar la homosexualidad femenina incluso entre los colectivos LGTBI. También urge tomar medidas que ayuden a reinterpretar la bisexualidad tanto entre la población general como entre los propios colectivos LGTBI, de manera que sea considerada como una orientación más y no como un estado de indecisión, transición o cobardía. La lucha contra los modelos categoriales de la orientación sexual debe ser feroz: tenemos que educar a la población respecto a la no necesidad de ponernos etiquetas que nos limiten, nos empobrezcan y no nos permitan crecer. El temor hacia la diversidad sexual debe ser sustituido por el respeto y admiración por las diversas formas de expresar y recibir el amor y el placer sexual y por las múltiples formas de crear una familia. Finalmente es importante recordar que una cosa es despatologizar y otra muy distinta dejar de cuidar. Desafortunadamente, estas ideas que hemos mostrado no son asumidas por toda la sociedad y las personas LGTBI están sometidas a una fuerte presión social y estigma que acaban interiorizando y afectándoles emocionalmente en muchos casos. Nuestra tarea no acaba educando a la población en estos valores, tenemos la obligación moral como profesionales de la salud mental de realizar un acompañamiento a través de terapias afirmativas de las personas LGTBI que sufren los efectos de la LGTBfobia y ayudarles a ser felices aunque no siempre los demás les den permiso para serlo.

\section{Referencias}

Alexander, J. y Anderlini-D'Onofrio, S. (2012). Bisexuality and Queer Theory. London: Routledge

Almeida, J., Johnson, R.M., Corliss, H.L., Molnar, B.E. y Azrael, D. (2009). Emotional Distress Among LGBT Youth: The Influence of Perceived Discrimination Based on Sexual Orientation. J. Youth Adolescence (2009) 38:1001-1014, DOI 10.1007/s10964-009-9397-9.

American Psychiatric Association (1958). Diagnostic and statistical manual of mental disorders (1ª edición) (DSM-I). Washington, D.C.: APA.

American Psychiatric Association (1973). Diagnostic and statistical manual of mental disorders (2ª edición) (DSMII). Washington, D.C.: APA. 
American Psychiatric Association (1980). Diagnostic and statistical manual of mental disorders (3ª edición) (DSMIII). Washington, D.C.: APA.

American Psychiatric Association (1988). Diagnostic and statistical manual of mental disorders (DSM-III-R). Washington, D.C.: APA.

American Psychiatric Association (1995). Diagnostic and statistical manual of mental disorders (DSM-IV). Washington, D.C.: APA.

American Psychiatric Association (2000). Diagnostic and statistical manual of mental disorders (DSM-IV-TR). Washington, D.C.: APA.

American Psychiatric Association (2013). Diagnostic and statistical manual of mental disorders (DSM-5). Washington, D.C.: APA.

Angelides, S. (2001). A history of bisexuality. Chicago: The University of Chicago Press.

Averett, P., Yoon, I. y Jenkins, C.L. (2013). Older Lesbian Experiences of Homophobia and Ageism. Journal of Social Service Research, 39:1, 3-15, DOI: 10.1080/01488376.2012.727671.

Avilés, J. M. (2006). Bullying: el maltrato entre iguales. Agresores, víctimas y testigos en la escuela. Salamanca: Amarú.

Badinter, E. (1993). XY: La identidad masculina. Madrid. Alianza editorial.

Ballester, R. y Gil, M.D. (1995). Homosexualidad: comportamientos, deseos y fantasías. Análisis y Modificación de Conducta, 76, 263-284.

Ballester-Arnal, R. (2020). Disfunciones sexuales, trastornos parafílicos y disforia de género. En A. Belloch, B. Sandín y F. Ramos, Manual de Psicopatología (vol.I), cap. 14. Barcelona: McGraw-Hill.

Ballester-Arnal, R. y Gil-Llario, M.D. (2016). Orientación del deseo sexual: crisis y decadencia de los modelos categoriales. En A. López de la LLave (Coord.): Sexología positiva: Placer, salud y bienestar (pp. 59-66). Madrid: Universidad Nacional de Educación a Distancia.

Bell, A.P. y Weinberg, M.S. (1978). Homosexualities. Nueva York: Simon and Schuster.

Bem, S. (1974). The measurement of psychological androgyny. Journal of Consulting and Clinical Psychology, 42, $155-162$.

Chard, A.N., Finneran, C., Sullivan, P.S. y Stephenson, R. (2015). Experiences of homophobia among gay and bisexual men: results from a crosssectional study in seven countries, Culture, Health \& Sexuality, 17:10, 1174-1189, DOI: 10.1080/13691058.2015.1042917

Cochran, G. (2008). An Evolutionary Look at Human Homosexuality. Descargado el 13 de septiembre de 2020 en: https:/wasdarwinwrong.com/feedback/An_Evolutionary_Look_at_Human_Homosexuality.htm

Cochran, S. D. (2001). Emerging issues in research on lesbians' and gay men's mental health: Does sexual orientation really matter? American Psychologist, 56, 931-947. DOl:10.1037/0003-066X.56.11.931

De Block, A. y Adriaens, P.R. (2013). Pathologizing sexual deviance: a history. The Journal of Sex Research, 50, 276298.

Fone, B. (2000). Homophobia: a history. Nueva York: Henry Holt and Company

Freud, S. (1905). Tres ensayos sobre la teoría de la sexualidad. Buenos Aires: Orbis

Freud, S. (1922). Ciertos mecanismos neuróticos en celos, paranoia y homosexualidad. Buenos Aires: Orbis

Friedman, C. y Leaper, C. (2010). Sexual-minority college women's experiences with discrimination: relations with identity and collective action. Psychology of Women Quarterly, 34, 152-164.

Halperin, D.M. (1990). One hundred years of homosexuality (and other essays on greek love). Nueva York: Routledge.

Hamer et al. (1993). A linkage between DNA markers on the X chromosome and male sexual orientation. Science, 261(5119), 321-7.

Kinsey, A.C., Pomeroy, W.B. y Martin, C.E. (1948). Sexual behavior in the human male. Philadelphia: Saunders Klein, F. (1978). The Bisexual Option: A Concept of One Hundred Percent Intimacy. EE UU: Arbor house. 
Kosciw, J.C., Greytak, E.A., Bartkiewicz, M.J., Boesen, M.J. y Palmer, N. A. (2011). The 2011 national school climate survey: The experiences of lesbian, gay, bisexual and transgender youth in our nation's schools. New York: Gay, Lesbian, \& Straight Education Network.

Krafft-Ebing, R. (1886). Psychopathia sexualis. Stuttgart: Verlag.

Lameiras, M, Carrera, M.V.y Rodríguez, Y. (2013). Sexualidad y salud: el estudio de la sexualidad humana desde una perspectiva de género. Vigo: Universidad de Vigo.

Lehavot, K. y Simoni, J.M. (2011). The Impact of Minority Stress on Mental Health and Substance Use Among Sexual Minority Women. Journal of Consulting and Clinical Psychology, 79, 2, 159-170. DOI: 10.1037/a0022839.

Meyer, I. H. (2003). Prejudice, Social Stress, and Mental Health in Lesbian, Gay, and Bisexual Populations: Conceptual Issues and Research Evidence. Psychological Bulletin, 129 (5): 674-697.

Mitchell, K.J., Ybarra, M.L., y Korchmaros, J.D. (2013). Sexual harassment among adolescents of different sexual orientations and gender identities. Child Abuse \& Neglect, 38, 280-295.

Mondimore, F.M. (1998). Una historia natural de la homosexualidad. Barcelona: Paidós

Moser, C. y Kleinplatz, P.J. (2008). DSM-IV-TR and the Paraphilias: an argument for removal. Journal of Psychology \& Human Sexuality, 17, 91-109.

Organización Mundial de la Salud (1992). CIE-10: Trastornos mentales y del comportamiento. Descripciones clínicas y pautas para el diagnóstico. Descargado el 18 de septiembre de 2020 en https://eciemaps.mscbs. gob.es/ecieMaps/browser/index_10_pcs.html.

Parsons, T. (1951). The social system. Michigan: Free Press

Platt, L.F.y Lenzen, A.L. (2013). Sexual Orientation Microaggressions and the Experience of Sexual Minorities, Journal of Homosexuality, 60:7, 1011-1034, DOI: 10.1080/00918369.2013.774878

Ray, N. (2006). Lesbian, gay, bisexual and transgender youth: An epidemic of homelessness. New York: National Gay and Lesbian Task Force Policy Institute and the National Coalition for the Homeless.

Rothman, E.F., Exner, D. y Baughman, A.L. (2011). The Prevalence of Sexual Assault Against People Who Identify as Gay, Lesbian, or Bisexual in the United States: A Systematic Review. Trauma, Violence \& Abuse, 12, 55-66.

Storms, M. D. (1980). Theories of sexual orientation. Journal of Personality and Social Psychology, 38(5), 783-792.

Swaab, DF y Hofman, MA (1990). An enlarged suprachiasmatic nucleus in homosexual men. Brain Research, 537 (1-2), 141-8.

Swaab, DF. y Falgueras, A.C. (2009). Brain Sex Differentiation (Sexual Differentiation of the Human Brain in Relation to Gender Identity). Descargado el 13 de septiembre de 2020 en: https://web.archive.org/ web/20130125045316/http://www.shb-info.org/sexbrain.html

Zinik, G. A. (1985). Identity conflict or adaptive flexibility? Bisexuality reconsidered. Journal of Homosexuality, 11(1/2), 7-19 